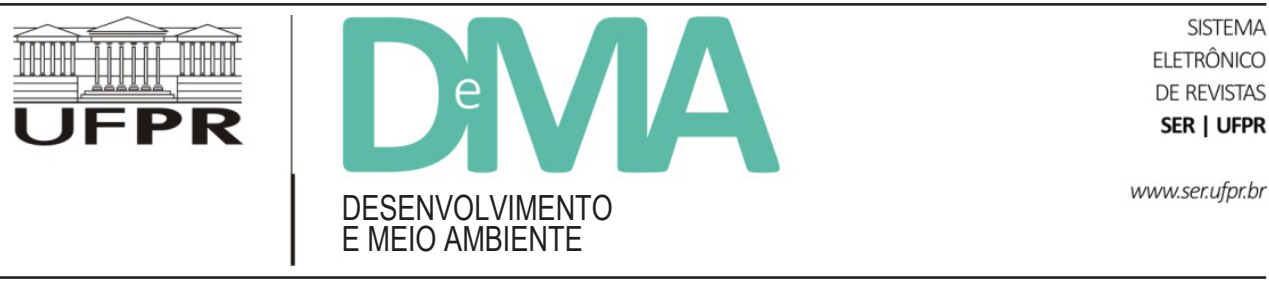

\title{
Proposta de criação de espaços territoriais a serem especialmente protegidos em uma zona de recarga do Sistema Aquífero Guarani no município de Ribeirão Preto, SP
}

\section{Proposal for Creation of Protected Areas in a Recharge Zone of the Guarani Aquifer System in Ribeirão Preto, Brazil}

\author{
Ligia Maria Barrios CAMPANHÃO ${ }^{1}$, Aurélio Teodoro FONTES ${ }^{2}$, Marcelo Pereira de SOUZA ${ }^{3}$ \\ ${ }^{1}$ Bióloga (USP). E-mail: ligiambc@hotmail.com \\ ${ }^{2}$ Doutor em Ciências da Engenharia Ambiental (USP). Pesquisador associado ao Núcleo de Política e Ciência Ambiental da Faculdade de \\ Filosofia, Ciências e Letras de Ribeirão Preto (FFCLRP) da Universidade de São Paulo (USP). E-mail: afontes@hotmail.com \\ ${ }^{3}$ Doutor em Saúde Pública (USP). Professor Titular da Faculdade de Filosofia, Ciências e Letras de Ribeirão Preto (FFCLRP) da Universidade \\ de São Paulo (USP). E-mail: mps@usp.br
}

Artigo: Recebido em: 21 de agosto de 2013; Versão final aceita em: 3 de fevereiro de 2014.

RESUMO O Sistema Aquífero Guarani (SAG) é considerado um dos maiores depósitos de água subterrânea do planeta e a maior parte de sua área está situada em território brasileiro. Em Ribeirão Preto, SP, o SAG aflora na zona leste do município, que o utiliza para o abastecimento urbano. Por outro lado, a presença de passivos ambientais e a impermeabilização do solo causada pela urbanização são uma ameaça à conservação do SAG no município, necessitando de medidas de gestão ambiental para garantir a qualidade e a quantidade da água do aquífero. Com vistas à conservação do SAG, o presente trabalho objetivou analisar a potencialidade de aplicação de espaços territoriais especialmente protegidos (ETEPs), tais como reservas legais (RL), área de preservação permanente (APP), Unidades de Conservação (UC), em áreas consideradas prioritárias pelo estudo de localização realizado por Bircol (2012). Os resultados apontam para um mosaico de ETEPs designados em função das características de cada local. Das 30 áreas estudadas, cinco foram enquadradas como UCs de Proteção Integral, oito em UCs de Uso Sustentável, oito em Zonas de Proteção Máxima (ZPM) e nove em parques urbanos públicos destinados ao lazer e à educação ambiental. Este trabalho mostrou que a instituição de ETEPs pode representar uma alternativa para buscar a conservação de uma das maiores reservas de água subterrânea do mundo, o Sistema Aquífero Guarani, compatibilizando a proteção com o desenvolvimento econômico e social.

Palavras-chave: espaços territoriais especialmente protegidos; Unidades de Conservação; Sistema Aquífero Guarani. 
ABSTRACT The Guarani Aquifer System (GAS) is considered one of the largest groundwater reservoirs in the world, and most of its area is located in Brazilian territory. In the municipality of Ribeirão Preto, SP, the GAS outcrops are in the eastern sector, which uses it for urban supply. On the other hand, the presence of environmental liabilities and soil compaction by urbanization are threats to the conservation of the GAS in the municipality, requiring environmental management measures to ensure the quality and quantity of water from the aquifer. Towards the GAS conservation, the present study aimed at analyzing the potential application of Brazilian protected areas (ETEPs), such as legal reserves (LR), permanent preservation areas (PPA), Conservation Units (CU), and in areas considered as priority by the location study accomplished by Bircol (2012). The results indicate a mosaic of ETEPs that are determined according to the characteristics of each site. Among the 30 areas studied, 5 were classified as Conservation Units of Integral Protection, 8 as Conservation Units of Sustainable Use, 8 as Zones of Maximum Protection (ZMP) and 9 as urban parks designated for public recreation and environmental education. This study shows that the institution of ETEPs may represent an alternative to seek the conservation of the Guarani Aquifer System, aligning protection with economic and social development.

Keywords: Protected areas; Conservation Units; Guarani Aquifer System.

\section{Introdução}

O Sistema Aquífero Guarani (SAG) é considerado um dos maiores depósitos de água subterrânea do planeta, com uma área total de $1.087 .879 \mathrm{~km}^{2}$ distribuídos entre Brasil, Argentina, Paraguai e Uruguai. A maior parte do SAG está situada em território brasileiro, o que o torna este país um grande responsável pela conservação desse sistema (OEA, 2009; Rebouças \& Amore, 2002).

Regionalmente, o planalto médio do Estado de São Paulo é um importante centro de reabastecimento do SAG. São $16.000 \mathrm{~km}^{2}$ de afloramento sedimentar das Formações Botucatu e Piramboia, pelos quais ocorre a percolação da água até a zona saturada do aquífero (Gomes et al., 2006). Com parte de seu território presente nesta área de recarga, mais especificamente a zona leste do município, Ribeirão Preto, SP, é conhecido por sua íntima relação com a dinâmica do aquífero.

Assim, Saes e Miyamoto (2012) discutem sobre o agravamento da degradação ambiental provocada pela atividade humana e os limites do uso da tecnologia para superar os problemas ambientais decorrentes, trazendo à tona a discussão dos limites do crescimento. Por sua vez, Coletti (2012) conclui sobre a necessidade do aprimoramento dos instrumentos, das técnicas e dos processos de comunicação para incentivar e garantir a participação da sociedade no processo de tomada de decisão. Nesse tema, Pizella e Souza (2012) corroboram essa conclu- são ao afirmarem que, no âmbito de regulamentação de OGMs - Organismos Geneticamente Modificados -, não existem boas práticas de governança ambiental no Brasil. Já Peccatiello (2011) comenta sobre a necessidade de consolidação de Política Pública pela efetivação de ações no tema Unidade de Conservação, apesar da existência de bons instrumentos de planejamento e gestão.

Especificamente no contexto do município de Ribeirão Preto, os problemas referentes à zona de recarga do SAG estão relacionados à crescente e acelerada urbanização que ocorre exatamente sobre esta área. Com isso, prevê-se que a urbanização, e a consequente impermeabilização do solo, culminarão em um declínio no nível do aquífero (Villar \& Ribeiro, 2009). Inclusive, toda a água de abastecimento urbano é proveniente deste manancial.

Além da quantidade, fatores qualitativos da água também devem ser considerados. Nesse aspecto, atualmente, o uso agrícola na região da zona leste, principalmente da monocultura de cana-de-açúcar, é um processo que pode contribuir para a poluição do aquífero. Segundo Gomes et al. (2006), estudos realizados pela Embrapa, entre 1994 e 2001, concluíram que grande parte dos agrotóxicos utilizados atualmente é potencialmente contaminante, em especial os utilizados no cultivo de cana-de-açúcar. Além disto, alguns estudos também constataram a contaminação das águas subterrâneas por compostos nitrogenados (Bonton et al., 2010; Zhang \& Hiscock, 2011). Por outro lado, o crescimento da urba- 
nização traz outros potenciais comprometimentos na qualidade da água, como o esgoto e produtos químicos oriundos de postos de gasolina, armazenamento, derramamentos por acidentes ou não.

Frente a esses impactos, e um movimento social local que congrega as organizações não governamentais e o poder público para a conservação da área e do aquífero, foram adotadas algumas medidas, como, por exemplo, o reconhecimento da zona leste como Zona de Uso Especial (ZUE). Esta zona possui caráter mais restritivo de uso e ocupação do solo, sendo instituída pelo Plano Diretor Municipal, estabelecido pela Lei Complementar $n^{\circ} 501$ de 1995. A partir de então, o Poder Público passou a exigir a destinação de 35\% da área total da Zona de Urbanização Restrita (ZUR), que corresponde à zona de expansão urbana localizada na ZUE, para implantação de áreas verdes, dentre outras determinações, o que a torna uma fonte de conflitos entre os proprietários de terras da região e o poder público e a sociedade.

Também com o propósito de conservar o SAG, foi criado o Grupo de Trabalho da Zona de Uso Especial (GT-ZUE), cujo objetivo era estabelecer normas e procedimentos relacionados ao uso e ocupação do solo na ZUE. A constituição desse grupo teve a iniciativa do Ministério Público do Estado de São Paulo que, dentre outras propostas, sugeriu a diminuição da zona de expansão urbana na região, a fim de evitar maiores impactos ao aquífero (GT-ZUE, 2010; Goulart et al., 2012).

De outra forma, certas determinações legais, como Áreas de Preservação Permanente (APP), que visam preservar os recursos hídricos e a estabilidade do solo, e Reservas Legais (RL), que procuram conservar e reabilitar os processos ecológicos, são frequentemente preteridas na ZUE, agravando ainda mais a situação desta área.

Assim, devido à necessidade de promover a infiltração de água de qualidade no SAG, conforme previsto pela Lei Complementar n ${ }^{\circ} 1616$ de 2004 (Código Municipal do Meio Ambiente), o GT-ZUE sugeriu que o Poder Público Municipal adotasse um planejamento global para a ZUE. Uma das propostas elencadas é a criação de um sistema de áreas verdes formado por parques e remanescentes florestais interligados, como forma de incrementar a cobertura vegetal na ZUE (GT-ZUE, 2010).

De fato, as florestas, rios e áreas alagadas prestam serviços ecossistêmicos de provisão e regulação do ciclo hidrológico. A vegetação desempenha um papel essencial no ciclo da água, pois a folhagem das plantas e a camada de serrapilheira funcionam como anteparos à água da chuva, reduzindo o impacto da mesma no solo. As raízes das plantas e os organismos também arejam o solo, aumentando a sua capacidade de absorção da água. Assim, a água pode infiltrar gradualmente, ao invés de atingir diretamente o solo, causando erosão e inundações (Primack \& Rodrigues, 2002; Sekercioglu, 2010).

Com relação à água subterrânea, muitas funções ecossistêmicas estão diretamente relacionadas ao armazenamento, recarga e descarga de aquíferos. O tipo de ecossistema e sua configuração podem determinar a taxa e a qualidade da recarga. Porém, essa relação intrínseca muitas vezes é desconhecida ou ignorada quando da tomada de decisão e gestão dos recursos hídricos e das bacias hidrográficas (Bergkamp \& Cross, 2006).

Neste contexto, Bircol (2012) realizou um estudo que fez uso dos critérios e da metodologia propostos por Ranieri (2004) para localizar as áreas mais aptas para comportar espaços territoriais especialmente protegidos. Os resultados geraram cenários prospectivos de áreas passíveis de serem protegidas.

O cenário apresentado evidencia a importância de medidas preventivas ante a situação em que a zona de recarga do SAG em Ribeirão Preto se encontra. Assim, aponta para a necessidade de minimizar e equacionar os conflitos na ZUE citados e de desenvolver medidas de proteção nesta área, com vistas à manutenção dos serviços ambientais exercidos pelos ecossistemas terrestres que estão diretamente relacionados com os atributos da água subterrânea.

Espaço Territorial Especialmente Protegido (ETEP) é o termo utilizado para se referir às diversas áreas protegidas previstas pela legislação brasileira. O termo é previsto pela Constituição Federal brasileira, no Artigo 225, $\S 1^{\circ}$, inciso III, como um dos instrumentos para assegurar o direito ao meio ambiente ecologicamente equilibrado. A Lei $\mathrm{n}^{\circ} 9985 / 00$ tinha como objetivo regulamentar os ETEPs, porém tratou apenas do Sistema Nacional de Unidades de Conservação (SNUC), não esclarecendo se 
os ETEPs citados no texto constitucional se referiam apenas às Unidades de Conservação (UCs) ou se poderiam incluir também outras áreas protegidas brasileiras, como as RLs, APPs, terras indígenas, dentre outras.

Neste trabalho, o conceito de ETEP adotado é o definido por Pereira e Scardua (2008), a fim de incluir não só as UCs, mas também outras áreas protegidas na avaliação a ser realizada. Estes autores defendem um conceito abrangente para os ETEPs, que seriam "[...] aqueles espaços, públicos ou privados, criados pelo poder público e que conferem proteção especial ao meio ambiente, tomado este em sua acepção mais ampla, de modo a incluir o aspecto cultural do meio ambiente" (Pereira \& Scardua, 2008, p. 90). Assim, UCs, terras indígenas, áreas tombadas, RLs, APPs, jardins botânicos, hortos florestais, dentre outros, poderiam compor ETEPs.

A partir do estudo de localização de áreas prioritárias para implantação, conservação e recuperação da vegetação na ZUE de Ribeirão Preto, elaborado por Bircol (2012), o presente trabalho objetiva: a) Indicar a modalidade de Espaço Territorial Especialmente Protegido (ETEP) apropriada para cada uma das áreas apontadas pelo já citado estudo de alocação, verificando a adequação para adotar cada uma das modalidades. b) Secundariamente, objetiva-se estabelecer diretrizes e/ ou prioridades para promover a conservação efetiva desses ecossistemas e de suas funções ambientais, especialmente as relativas ao ciclo hidrológico. Para isto, serão utilizados imagens de sensoriamento remoto e sistema de informação geográfica aplicados à ecologia da paisagem. Assim, pretende-se obter um mosaico de áreas protegidas, em consonância com os princípios de um planejamento ambiental voltado ao desenvolvimento sustentável.

\section{Material e métodos}

Aárea de estudo é a Zona de Uso Especial de Ribeirão Preto, SP, localizada a nordeste do município (Figura 1). São aproximadamente $137 \mathrm{~km}^{2}$ de afloramento das Formações Botucatu e Piramboia, nas quais ocorre a recarga do aquífero Guarani (OEA, 2009).

Bircol (2012) realizou um estudo que fez uso dos critérios e da metodologia propostos por Ranieri (2004) para localizar as áreas mais aptas para comportar espaços territoriais especialmente protegidos, buscando recompor o equilíbrio ecológico da região e a proteger o SAG. Foram utilizados os seguintes critérios no trabalho de Bircol (2012): Manutenção de fragmentos de vegetação existentes; Proteção de áreas mais suscetíveis à erosão; Aumento dos fragmentos existentes; Alargamento das faixas de vegetação ao longo de corpos d'água; Proteção de cabeceiras de bacias; Redução das distâncias entre fragmentos; Proteção de áreas de recarga de aquíferos. O tratamento das informações e obtenção dos resultados foi realizado com o uso de Sistema de Informação Geográfica (SIG), software IDRISI Taiga.

Os resultados geraram cenários prospectivos de áreas passíveis de serem protegidas, sendo que um dos cenários contemplou todos os graus de prioridade e, assim, conseguiu atingir um nível satisfatório de áreas a serem protegidas. É a partir deste cenário, apresentado na Figura 2, que o presente trabalho irá propor a designação das diferentes categorias de proteção.

A partir da Figura 2, foram identificadas 30 áreas prioritárias contínuas, sendo que muitas delas incluem remanescentes de vegetação e áreas de APP. A fim de determinar as modalidades de ETEPs, cada uma destas áreas prioritárias foi avaliada segundo:

I) A Influência da expansão urbana: neste tópico, foi apurado o grau de inserção de cada área e de sua respectiva zona de amortecimento (ZA) na zona urbana (ZU), zona de expansão urbana (ZEU) e zona rural (ZR). Foi estabelecida como zona de amortecimento uma faixa de três mil metros a partir do limite da respectiva área, largura esta determinada pela Resolução CONAMA n ${ }^{\circ}$ 428/2010, que dispõe sobre a largura da ZA em UCs que ainda não dispõem de Plano de Manejo.

II) O potencial da área para preservação ou conservação: utilizando alguns princípios clássicos propostos pela ecologia de paisagem para a seleção e desenho de reservas, particularmente os reunidos por Shafer (1997), foram coletados os seguintes dados acerca das características bióticas das áreas:

a) A fisionomia dos fragmentos remanescentes, caso os mesmos estivessem incluídos nas áreas determinadas. Foram utilizados os dados disponibilizados por Kotchetkoff-Henriques (2003). 


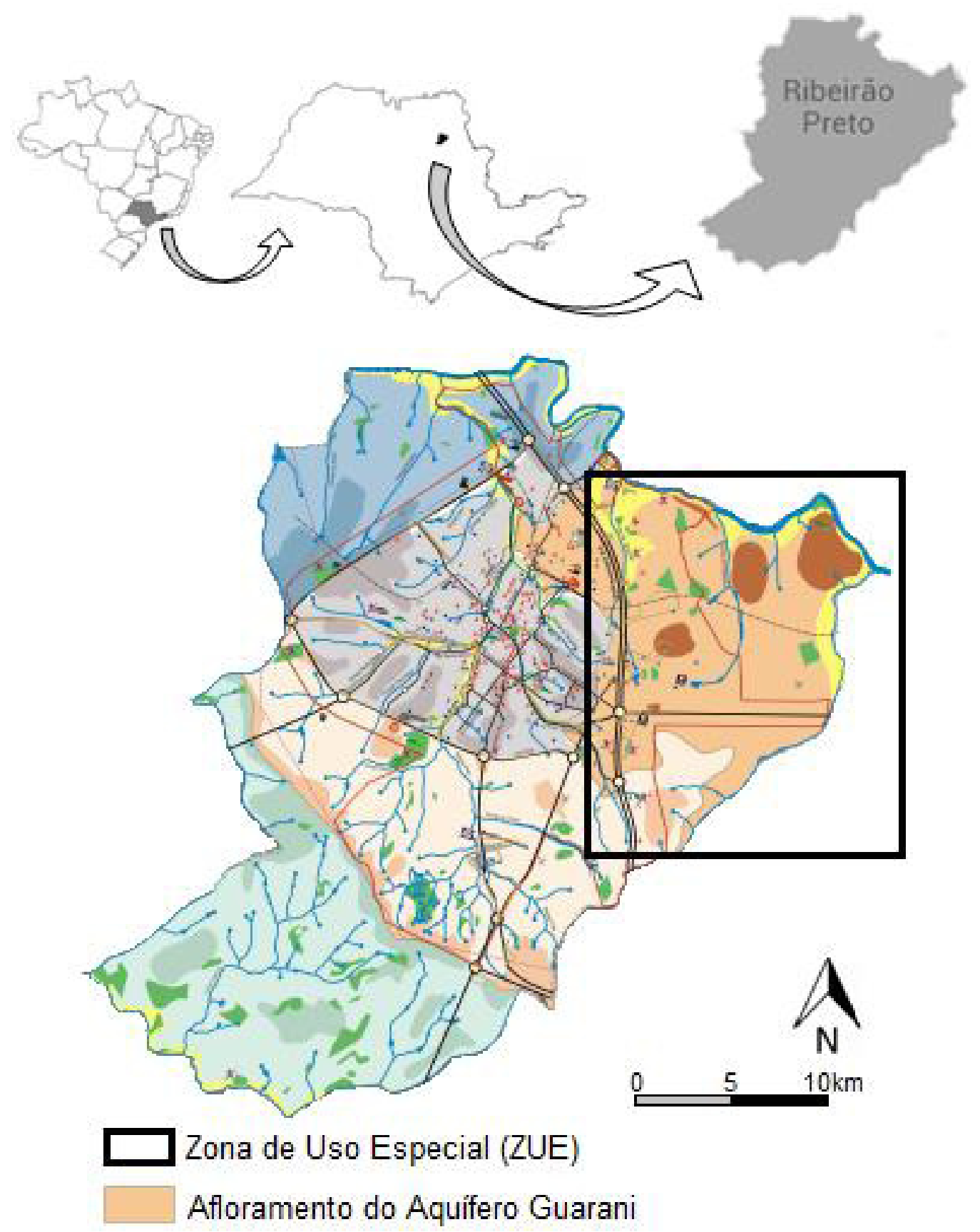

FIGURA 1 - Localização do município de Ribeirão Preto no Estado de São Paulo, bem como a carta ambiental do Plano Diretor municipal, destacando a Zona de Uso Especial - ZUE, objeto de estudo deste trabalho.

FONTES: Adaptado de IBGE (2013) e Ribeirão Preto (2007). 


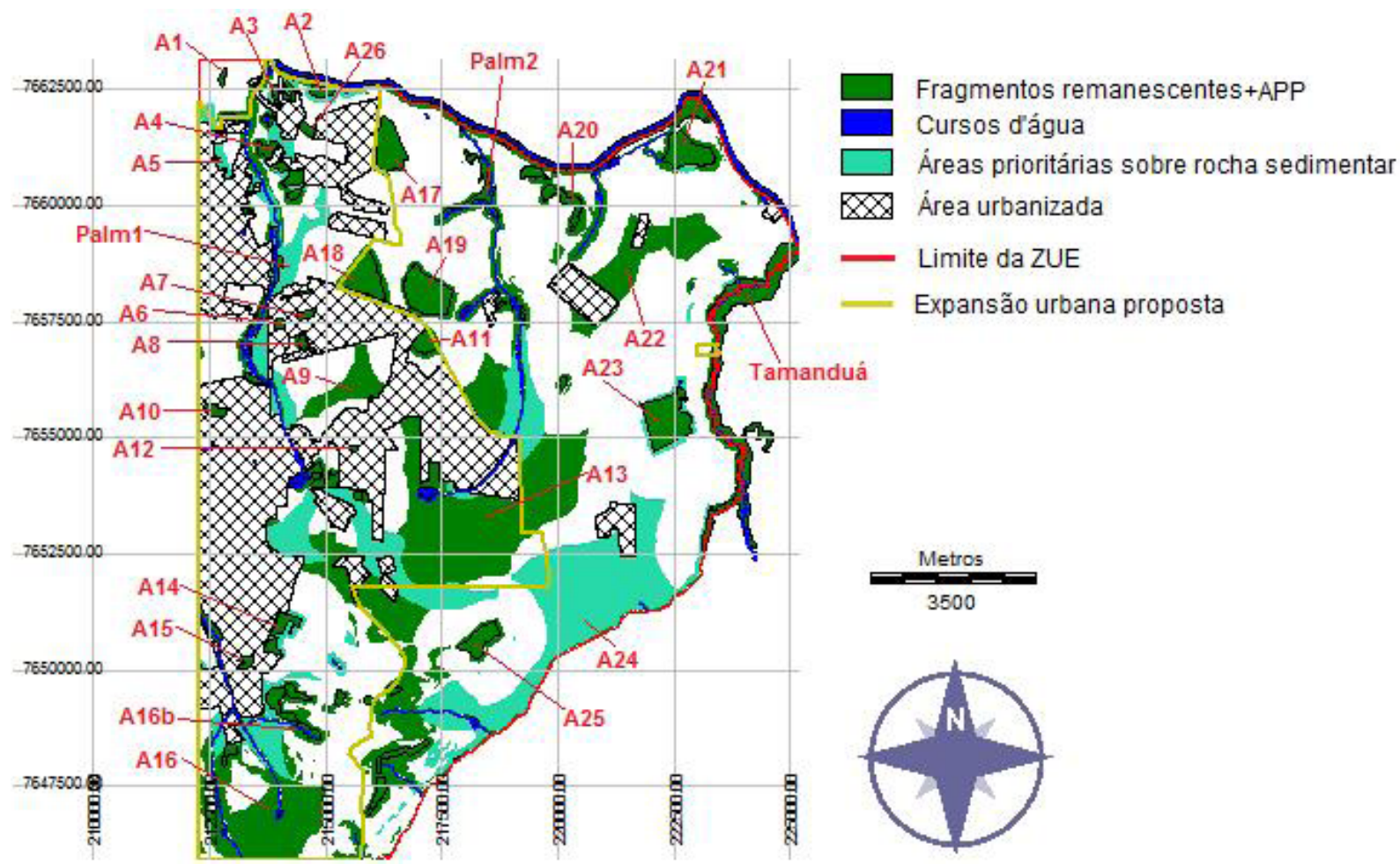

FIGURA 2 - Cenário com as indicações das áreas a serem protegidas na zona leste de Ribeirão Preto.

FONTE: adaptado de Bircol (2012).

(Legenda: APP - Área de Preservação Permanente, ZUE - Zona de Uso Especial).

b) A possibilidade de a área abrigar habitats diversificados por meio da proteção de morros, lagos, florestas, etc. (Shafer, 1997).

c) O formato e extensão da área, visto que áreas alongadas acumulam mais efeito de borda, enquanto que áreas mais arredondadas possuem maior área livre desse efeito. Dentro deste tópico também foi apurado o grau de isolamento da área, ou seja, se ela está próxima de outras áreas prioritárias ou se está totalmente inserida em área urbanizada, onde edificações e rodovias são impedimentos ao deslocamento da biota (Shafer, 1997).

d) A descrição na literatura sobre a presença de espécies da fauna e flora raras, ameaçadas ou endêmicas. Devido à carência de estudos sobre a biota da região de estudo, foram utilizados somente os valores de conservação (VC) determinados no trabalho de caracterização vegetal realizado por Kotchetkoff-Henriques (2003). Neste estudo, foi feito o diagnóstico da vegetação natural da maioria dos fragmentos remanescentes do município de Ribeirão Preto, SP. Estes fragmentos puderam ser hierarquizados de acordo com sua importância para a conservação a partir da inferência dos respectivos VC. Este índice é subdividido em valor de conservação biológico (VB), onde são considerados fatores biológicos como riqueza de espécies e proporção de espécies de ocorrência rara, e valor de conservação espacial (VE), onde são considerados fatores espaciais como 
área do fragmento, proporção de área core e índice de similaridade.

e) A presença de rocha sedimentar (arenito) e, consequentemente, área de recarga do Aquífero Guarani.

Dessa forma, a partir das características ecossistêmicas e do grau de inserção no perímetro urbano, as áreas foram qualificadas segundo potencial para preservação ou conservação. Para a coleta de alguns dados e ilustração das áreas, foram utilizadas imagens disponibilizadas pelo software Google Earth, as quais foram coletadas no mês de setembro de 2012 e em 08 de maio de 2013.

O objetivo básico das UC de Proteção Integral é a preservação da natureza, permitindo o uso indireto dos recursos naturais. Já o objetivo das UC de Uso Sustentável é compatibilizar a conservação da natureza com o uso indireto de alguns dos recursos naturais (Brasil, 2000). De acordo com o potencial para preservação ou conservação de cada área, foi possível inferir qual categoria de UC era aplicável em cada caso, utilizando dois quadros comparativos elaborados de acordo com a legislação que trata do SNUC (Lei no 9985/00 e Decreto $\left.\mathrm{n}^{\circ} 4340 / 02\right)$. O primeiro quadro comparava os diferentes objetivos que podem ser obtidos por cada tipo diferente de UC e o segundo quadro comparava as características de cada tipo de UC.

Nas áreas cujo potencial para preservação e conservação era baixo ou havia total inclusão no perímetro urbano, tornando inaplicável a implantação de UCs, houve o enquadramento em outros tipos de ETEPs, inclusive os Municipais, previstos em legislação específica. Para tanto, foi realizada a caracterização do entorno destas áreas em residencial, comercial ou industrial, a fim de determinar o ETEP que melhor se aplicasse à possibilidade de uso público ou não. A Figura 3 a seguir ilustra resumidamente todo o processo de identificação do ETEP.

\section{Resultados e discussão}

Dentre as 30 diferentes áreas prioritárias contínuas determinadas por Bircol (2012), treze foram enquadradas como Unidades de Conservação, sendo cinco de Proteção

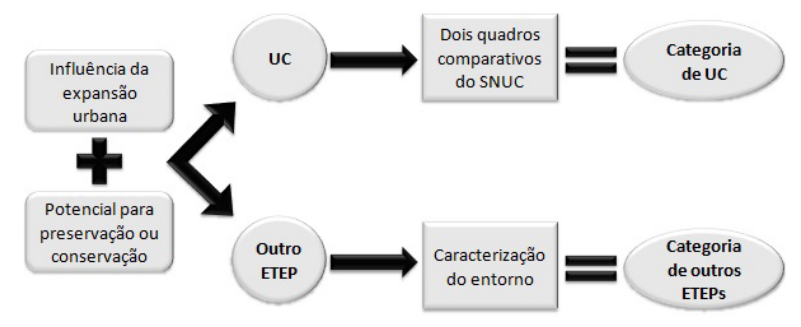

FIGURA 3 - Esquema representativo da metodologia utilizada.

(Legenda: UC - Unidade de Conservação, ETEP - Espaço territorial especialmente protegido, SNUC - Sistema Nacional de Unidades de Conservação).

Integral e oito de Uso Sustentável. Os outros tipos de ETEPs determinados foram oito Zonas de Proteção Máxima (ZPM) e nove parques urbanos, ambas modalidades de ETEP municipal. A Figura 4 mostra a distribuição de cada modalidade de ETEP nas 30 áreas.

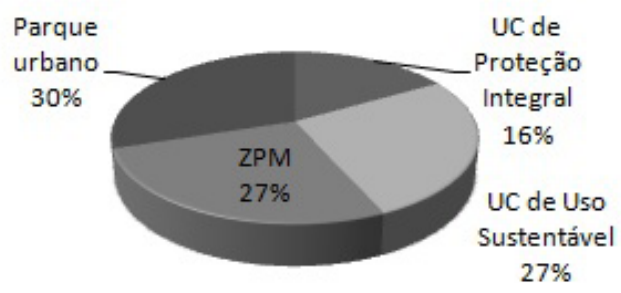

FIGURA 4 - Porcentagem de cada tipo de Espaço Territorial Especialmente Protegido - ETEP - determinado nas 30 áreas prioritárias.

Os resultados foram dispostos nas Tabelas 1 a 6 , conforme os diferentes tipos de ETEPs determinados. Em cada tabela pode-se identificar as áreas, a qual categoria foram destinadas e o conjunto de dados gerais que permitiram o enquadramento.

De acordo com a Tabela 1, três áreas foram enquadradas como EE, em razão de suas características ecossistêmicas e localização privilegiada. Um exemplo destas áreas é a área A23, localizada em ZR, em uma região onde não há pressão da expansão urbana. $\mathrm{O}$ potencial para preservação desta área é alto, pois está situada sob a zona de recarga do SAG e engloba um remanescente de cerrado de importância municipal, devido à sua riqueza 
de espécies vegetais e alta proporção de ocorrência de espécies vegetais raras, segundo seu VB ( $2^{\circ}$ maior $)$ determinado por Kotchetkoff-Henriques (2003). Além destas características, a área é muito próxima da área prioritária Tamanduá, que inclui a APP de um pequeno córrego, o que permite a conectividade na paisagem. A Figura 5 ilustra a área A23 em particular e sua respectiva imagem de satélite.

As duas áreas propostas para integrar Parque Natural Municipal - PARNA, conforme descrito na Tabela 2, abrigam dois remanescentes de cerrado muito próximos entre si, separados pela área de um assentamento rural. Estas áreas têm alto potencial para preservação, em especial a área A18, que abriga o fragmento com maior VB do município, em razão da elevada proporção de espécies de ocorrência rara (Kotchetkoff-Henriques, 2003). Apesar de estarem localizadas em ZR, se encontram muito próximas de residências, situando-se em área sob a influência da expansão urbana. Devido à necessidade de preservar estes remanescentes, relevantes ecologicamente no contexto municipal, e de promover a inclusão dos moradores do entorno com estas áreas, a implantação de um PARNA constitui uma opção, pois seu objetivo visa tanto à preservação do ecossistema quanto à visitação pública. A Figura 6 ilustra estas duas áreas e a respectiva imagem de satélite.

\section{TABELA 1 - ÁREAS ENQUADRADAS COMO UNIDADE DE CONSERVAÇÃO DE PROTEÇÃO INTEGRAL DO TIPO ESTAÇÃO}

ECOLÓGICA - EE

\begin{tabular}{|c|c|c|l|}
\hline $\begin{array}{c}\text { Modalidade de } \\
\text { ETEP }\end{array}$ & Categoria & Áreas & Características que determinaram o enquadramento \\
\hline $\begin{array}{c}\text { UC de Proteção } \\
\text { Integral }\end{array}$ & $\begin{array}{c}\text { Estação } \\
\text { Ecológica (EE) }\end{array}$ & A23 & $\begin{array}{l}\text { Estas áreas possuem alto potencial para preservação, principal- } \\
\text { mente por situarem-se sobre arenito, possuírem altos índices de } \\
\text { VC e localização favorável em ZR. Outras características que de- } \\
\text { terminaram o enquadramento foram: formato arredondado (A23), } \\
\text { presença de fragmentos remanescentes de cerrado (A23 e A21), } \\
\text { proximidade com outras áreas (Tamanduá) e potencial em abrigar } \\
\text { diferentes habitats (A21). }\end{array}$ \\
\hline
\end{tabular}

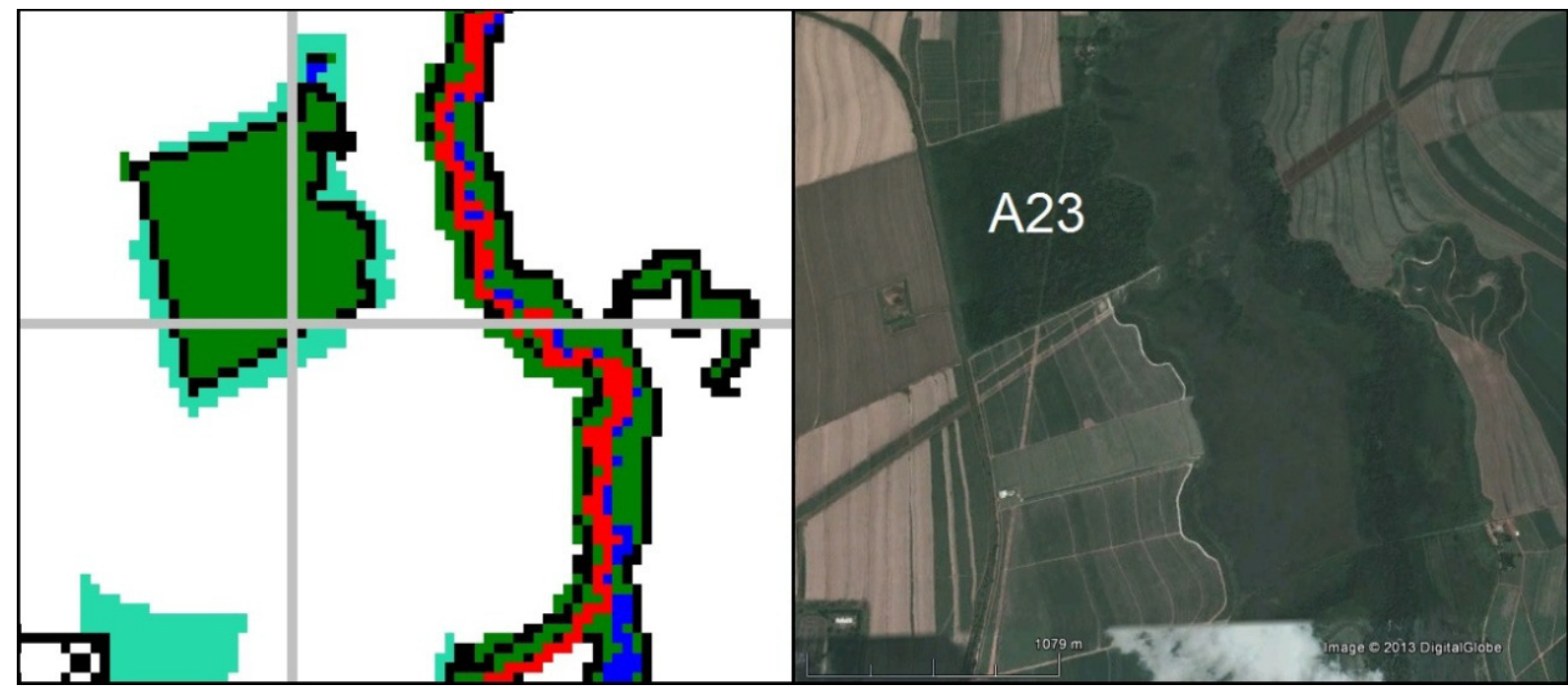

FIGURA 5 - Área A23 em destaque, proposta como Estação Ecológica - EE. FONTE: Google Earth (2013). 
TABELA 2 - ÁREAS ENQUADRADAS COMO UNIDADE DE CONSERVAÇÃO DE PROTEÇÃO INTEGRAL DO TIPO PARQUE NATURAL MUNICIPAL - PARNA

\begin{tabular}{|c|c|c|c|}
\hline Modalidade de ETEP & Categoria & Áreas & $\begin{array}{c}\text { Características que determinaram o } \\
\text { enquadramento }\end{array}$ \\
\hline UC de Proteção Integral & $\begin{array}{c}\text { Parque Natural } \\
\text { Municipal (PARNA) }\end{array}$ & A18 & $\begin{array}{l}\text { Alto potencial para a preservação, devido à presença de } \\
\text { fragmentos de cerrado com altos VC (4a e 9a posição), } \\
\text { proximidade com outras áreas prioritárias e formato arre- } \\
\text { dondado (A19). São muito próximas de residências. }\end{array}$ \\
\hline
\end{tabular}

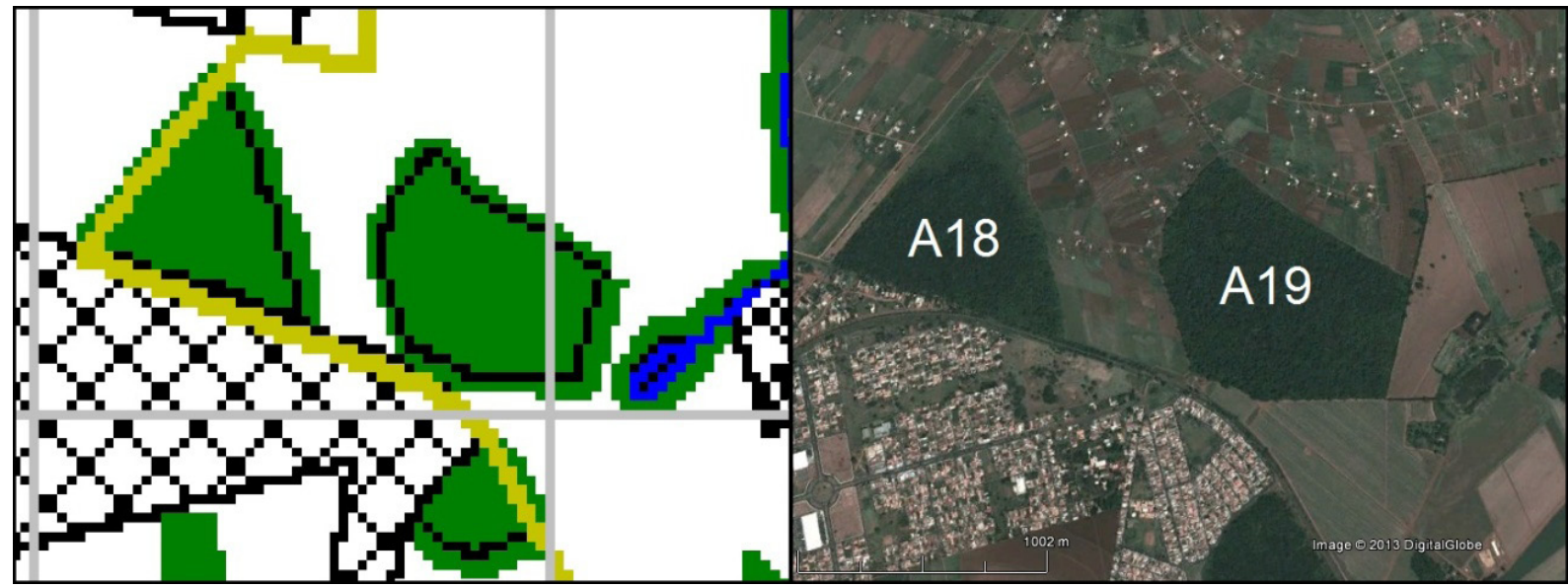

FIGURA 6 - Áreas A18 e A19 em destaque, propostas como Parque Natural Municipal - PARNA.

FONTE: Google Earth (2013).

De acordo com a Tabela 3, três áreas foram propostas para compor Áreas de Relevante Interesse Ecológico - ARIEs. Dentre elas, a área A17 inclui um fragmento de cerrado limítrofe à área urbana. Devido à localização desfavorável e potencial apenas para conservação, e não preservação, uma UC de Uso Sustentável é aplicável. A
ARIE apresenta-se como modalidade mais adequada, pois visa regular o uso admissível dos ecossistemas de relevância local ou regional, de forma a permitir sua manutenção e conservação. A Figura 7 ilustra a área A17, juntamente com sua imagem de satélite.

TABELA 3 - ÁREAS ENQUADRADAS COMO UNIDADE DE CONSERVAÇÃO DE USO SUSTENTÁVEL DO TIPO ÁREA DE RELEVANTE INTERESSE ECOLÓGICO - ARIE

\begin{tabular}{|c|c|c|c|}
\hline Modalidade de ETEP & Categoria & Áreas & Características que determinaram o enquadramento \\
\hline UC de Uso Sustentável & $\begin{array}{c}\text { Área de } \\
\text { Relevante } \\
\text { Interesse } \\
\text { Ecológico } \\
\text { (ARIE) }\end{array}$ & A20 17 & $\begin{array}{l}\text { Estas áreas apresentam potencial para a conservação, devido à } \\
\text { potencialidade em abrigar diferentes habitats (A20), proximi- } \\
\text { dade com outras áreas prioritárias (todas) e localização sobre } \\
\text { arenito (Palm2). Todas se localizam próximas de residências. }\end{array}$ \\
& Palm2 & \\
\hline
\end{tabular}




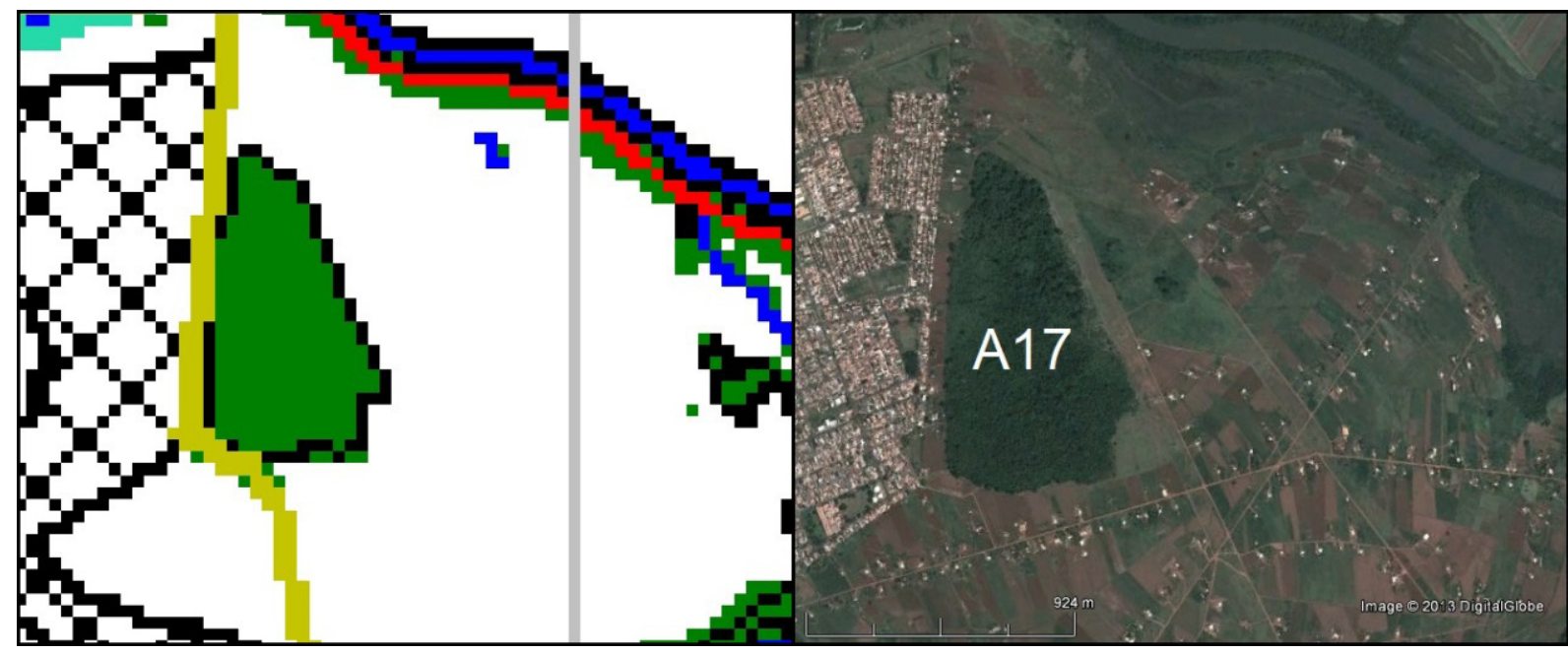

FIGURA 7 - Área A17 em destaque, proposta como Área de Relevante Interesse Ecológico - ARIE.

FONTE: Google Earth (2013)

Todas as áreas propostas como Área de Proteção Ambiental - APA, listadas na Tabela 4, possuem as mesmas características gerais e apenas uma não se localiza sobre a zona de recarga do SAG (A22). Como pode ser verificado na Figura 8, que ilustra a área Palm1 e sua imagem de satélite, o território abrange uma variedade de usos do solo, como: fragmentos de vegetação, APP de um córrego, parte de um assentamento rural, plantação agrícola, dentre outros, caracterizando-se como área de alto grau de ocupação humana localizada justamente sobre a zona de recarga do SAG.

Como exemplo de área proposta para integrar Zona de Proteção Máxima - ZPM, a área A14 (Figura 9) situa-se na zona de expansão urbana do município e abriga dois fragmentos de cerrado. Assim como as outras áreas determinadas como ZPM, descritas na Tabela 5, a área A14 tem potencial baixo para preservação e conservação e, devido à sua vizinhança majoritariamente comercial, também não tem potencial para uso público.

TABELA4 - ÁREAS ENQUADRADAS COMO UNIDADE DE CONSERVAÇÃO DE USO SUSTENTÁVEL DO TIPO ÁREA DE PROTEÇÃO AMBIENTAL - APA

\begin{tabular}{|c|c|c|l|}
\hline Modalidade de ETEP & Categoria & Áreas & \multicolumn{1}{|c|}{ Características que determinaram o enquadramento } \\
\hline UC de Uso Sustentável & Área de & A13 & As áreas determinadas nesta categoria caracterizam-se por abrigar \\
& Proteção & A24 & diversos tipos de uso do solo e possuir certo grau de ocupação \\
& Ambiental & A16 & humana, havendo a necessidade de promover o disciplinamento \\
& (APA) & Palm1 & \\
& & A22 & \\
\hline
\end{tabular}




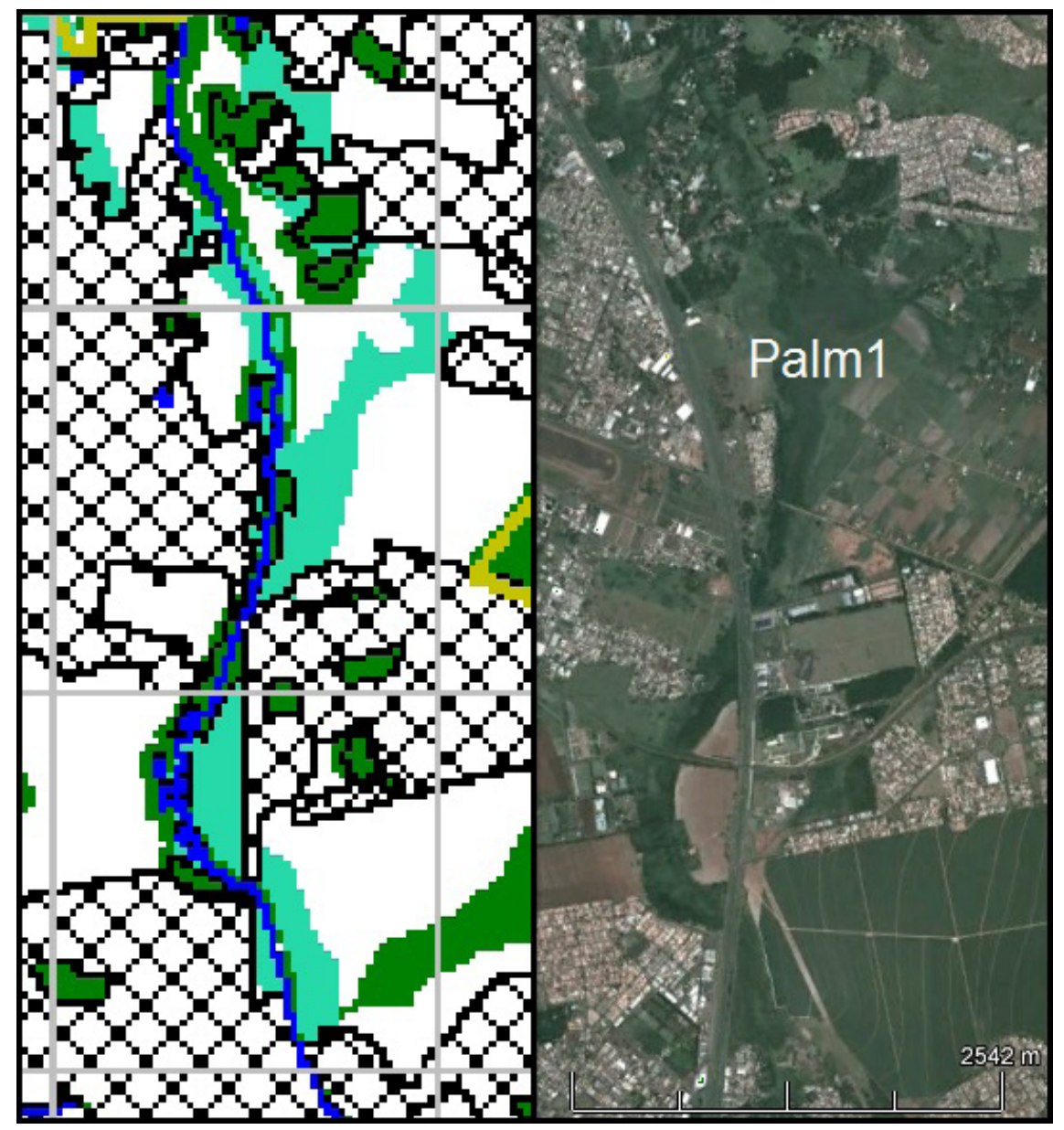

FIGURA 8- Área Palm1 em destaque, proposta como Área de Proteção Ambiental - APA.

FONTE: Google Earth (2013).

TABELA 5 - ÁREAS ENQUADRADAS COMO ZONA DE PROTEÇÃO MÁXIMA - ZPM

\begin{tabular}{|c|c|c|l|}
\hline $\begin{array}{c}\text { Modalidade de } \\
\text { ETEP }\end{array}$ & Categoria & Áreas & Características que determinaram o enquadramento \\
\hline ETEP municipal & Zona de Proteção & A1 & Estas áreas determinadas como ZPM caracterizam-se, no ge- \\
& Máxima (ZPM) & A2 & ral, em pequenos remanescentes de vegetação, alguns total- \\
& & A3 & mente inseridos em malha urbana. Não apresentam alto po- \\
& & A5 & tencial para preservação ou conservação e também têm baixo \\
& & A6 6 & (A25) ou vizinhança majoritariamente comercial (A5 e A14) \\
& & A7 & e industrial (A6 e A7). \\
& & A14 & \\
& & A25 & \\
\hline
\end{tabular}




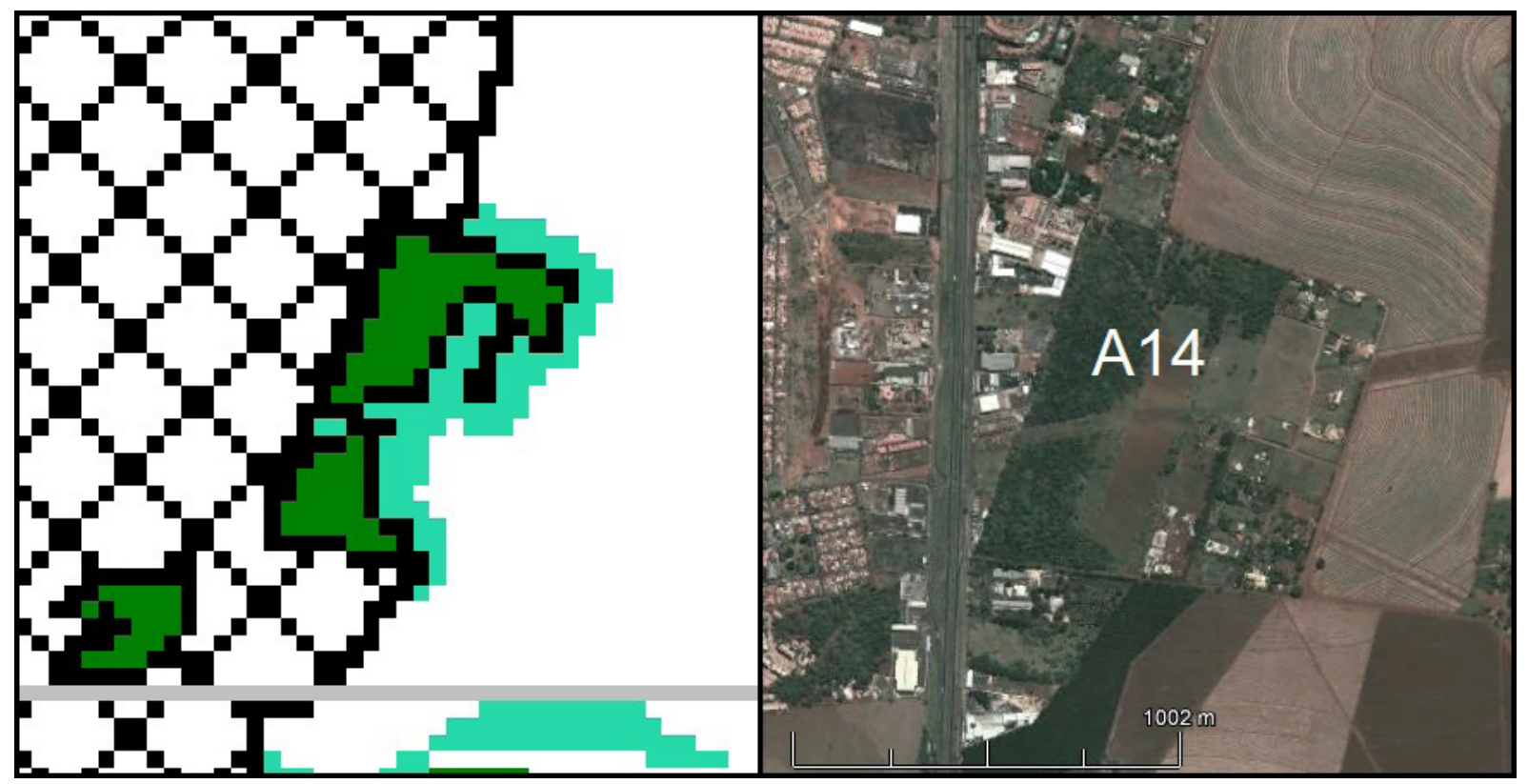

FIGURA 9 - Área A14 em destaque, proposta como Zona de Proteção Máxima - ZPM.

FONTE: Google Earth (2013).

A Tabela 6 apresenta as áreas enquadradas como Parque Urbano. Como exemplo deste tipo de ETEP, a área A10 (Figura 10) está inserida na zona urbana do município, circundada por residências. Compreende o Morro da Vitória, que abriga um fragmento de floresta estacional decidual. Nesta área funcionava um parque chamado "Cidade das Crianças", porém, hoje o local está abandonado e muito depredado.
O mosaico de ETEPs resultante é constituído por uma variedade de áreas protegidas, de caráter mais restritivo como UCs de Proteção Integral e menos restritivo como parques urbanos de uso público. Dessa forma, a proteção legal é aplicável na área de estudo por meio do Sistema de Unidades de Conservação e também da legislação municipal, que dispõe de outros espaços protegidos além dos previstos pela legislação federal.

TABELA 6 - ÁREAS ENQUADRADAS COMO PARQUE URBANO

\begin{tabular}{|c|c|c|c|}
\hline $\begin{array}{c}\text { Modalidade de } \\
\text { ETEP }\end{array}$ & Categoria & Áreas & Características que determinaram o enquadramento \\
\hline ETEP municipal & Parque Urbano & $\begin{array}{c}\text { A4 } \\
\text { A8 } \\
\text { A9 } \\
\text { A10 } \\
\text { A11 } \\
\text { A12 } \\
\text { A15 } \\
\text { A26 } \\
\text { A16b }\end{array}$ & $\begin{array}{l}\text { Todas estas áreas estão muito próximas de residências ou } \\
\text { totalmente inseridas no perímetro urbano e abrigam remanes- } \\
\text { centes de vegetação (exceto área A9). Dentre elas há um parque } \\
\text { urbano abandonado (A10), áreas situadas sobre arenito (A4) e } \\
\text { também um fragmento de cerrado com alto VC }\left(10^{\mathrm{a}}\right) \text { que está } \\
\text { totalmente isolado de outros remanescentes por uma ferrovia } \\
\text { (A11). }\end{array}$ \\
\hline
\end{tabular}




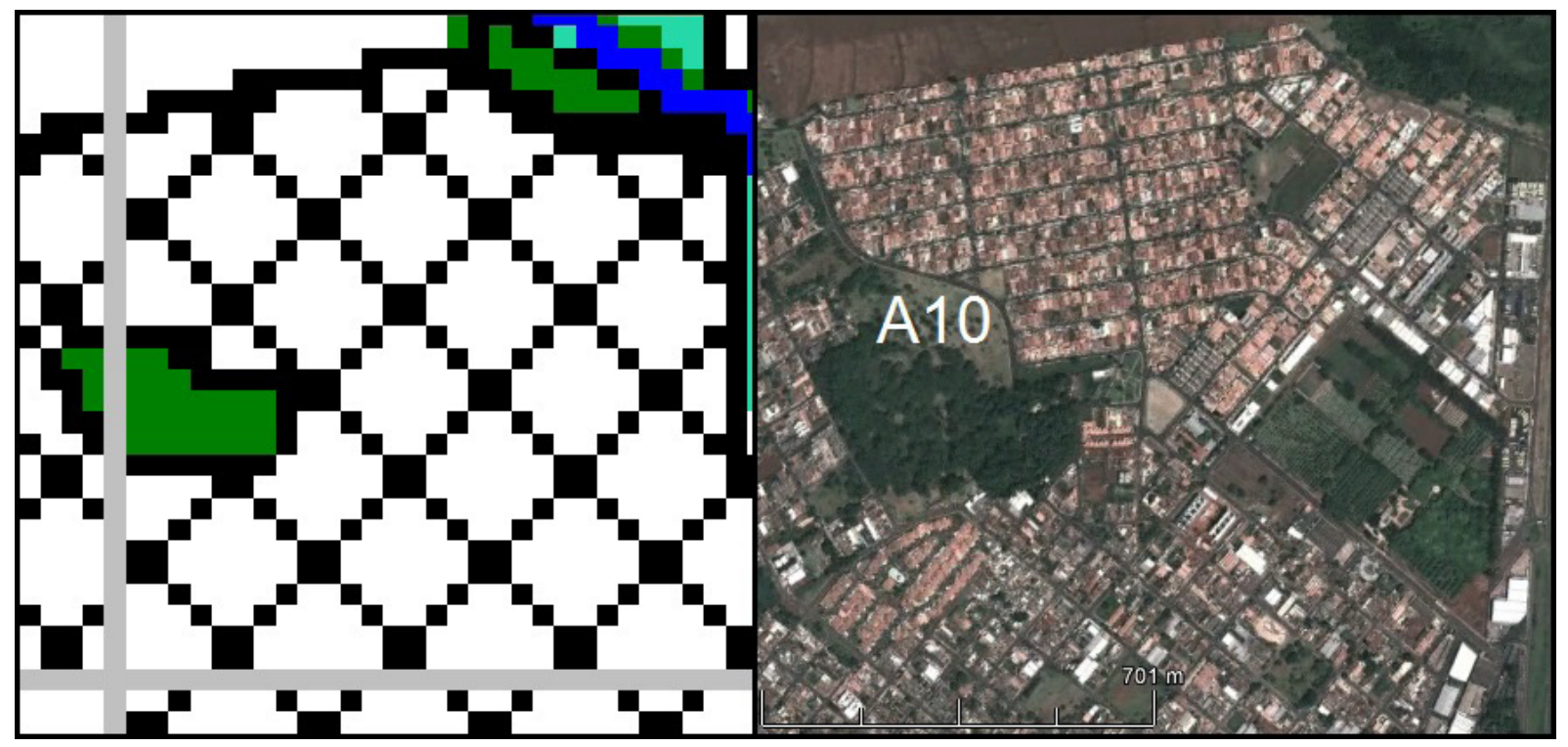

FIGURA 10 - Área A10 em destaque, proposta como Parque Urbano. FONTE: Google Earth (2013).

A Figura 11, que mostra a distribuição espacial dos ETEPs na ZUE, permite a inferência do grau de proteção que o cenário passa a ter. Com a implantação do mosaico, $36,32 \%$ de toda a ZUE ficaria amparada pela proteção legal na forma destes espaços (Bircol, 2012).

As áreas determinadas como UCs, segundo o Sistema Nacional de Unidades de Conservação (SNUC), devem ser adequadas ao que dispõe a legislação, a fim de que os objetivos destes espaços protegidos sejam alcançados. Dessa forma, é importante que diretrizes e prioridades sejam estabelecidas para a implementação e gestão destas áreas.

Devido à carência de estudos sob o meio biológico na região, é muito importante que se realizem estudos técnicos a fim de levantar dados acerca da fauna e flora local e também dados de cunho abiótico e socioeconômico. A consulta pública também deve ser realizada, pois é instrumento que permite o debate, questionamentos e esclarecimentos, agilizando o processo (Leite et al., 2001). Assim, o processo de criação se torna transparente e participativo, evitando que futuros conflitos surjam durante as etapas de implantação e gestão da UC.
O Plano de Manejo, documento previsto pela lei do SNUC, é obrigatório para todas as UCs determinadas. Sua elaboração deve ser prioridade após a criação da Unidade, visto que, com ausência de manejo, a área fica exposta às pressões exercidas pelas atividades antrópicas $\mathrm{e}$, muitas vezes, atividades que não pactuam com o regime da Unidade são exercidas em seu interior, causando danos e impactos ambientais.

Todas as categorias de UCs determinadas no presente trabalho, exceto a APA, devem dispor de Zona de Amortecimento. A área de estudo engloba uma zona rural que sofre pressões de todas as ordens, notadamente expansão da atividade agrícola e expansão do perímetro urbano. Portanto, é muito importante que seja realizado um diagnóstico detalhado da área a ser incorporada como Zona de Amortecimento (ZA) de cada Unidade proposta, observando qual o limite mais adequado a cada tipo de $\mathrm{UC}$ e à realidade local, de acordo com critérios físicos, socioeconômicos, culturais, de uso e cobertura do solo, dentre outros (Ribeiro et al., 2010).

Além de ser paisagem altamente modificada pelas atividades humanas, a área de estudo está inserida em 


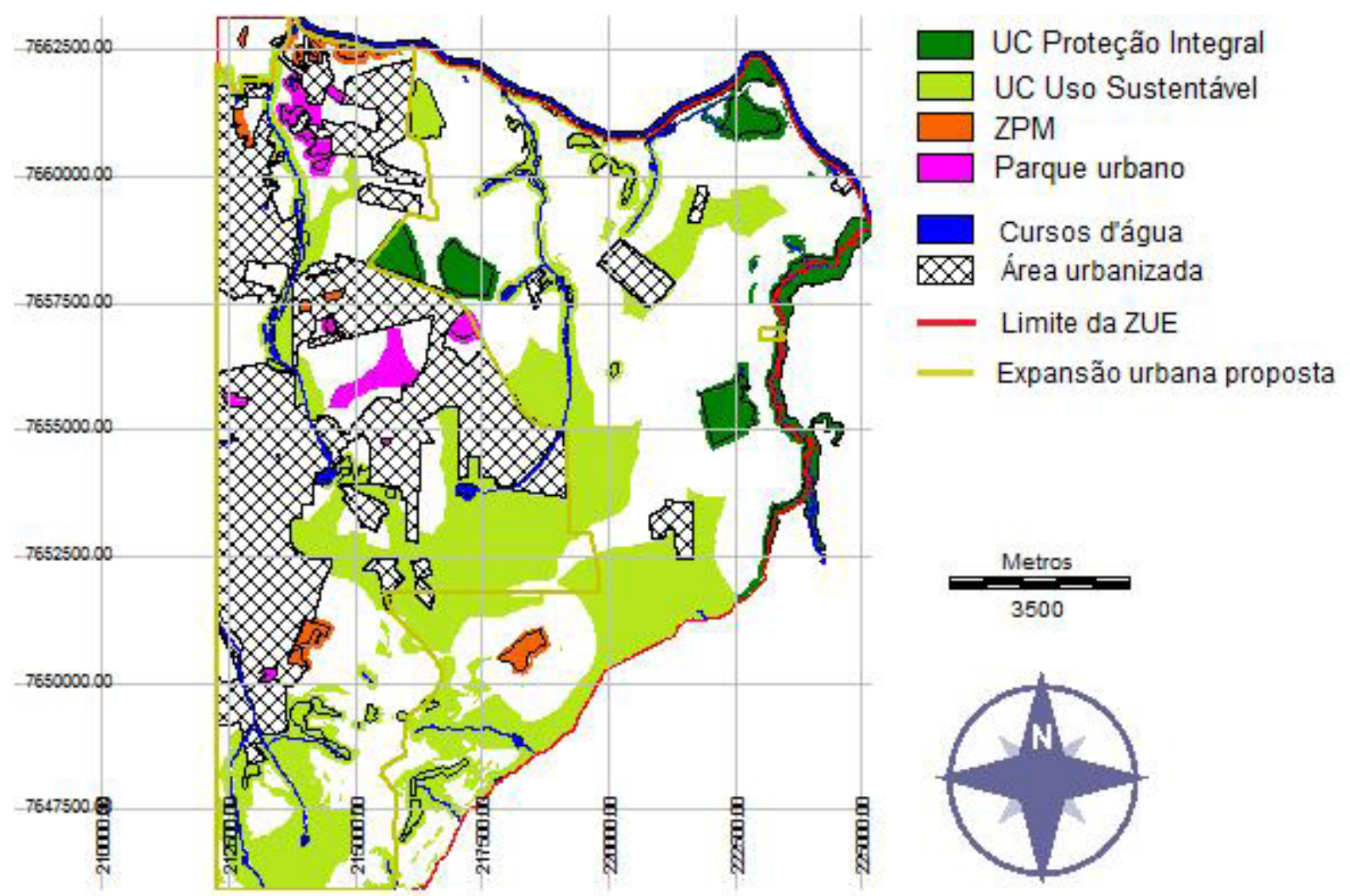

FIGURA 11 - Distribuição espacial dos diferentes tipos de Espaço Territorial Especialmente Protegido -ETEPs - determinados na Zona de Uso Especial - ZUE.

(Legenda: UC - Unidade de Conservação; ZPM - Zona de Proteção Máxima; ZUE - Zona de Uso Especial).

um município onde apenas 3,28\% do território é constituído por vegetação natural (São Paulo, 2009) e um único cultivo, a cana-de-açúcar, ocupa a maior parte do território (Kotchetkoff-Henriques, 2003). A própria ZUE possui grandes canaviais e é considerada uma região promissora para a expansão urbana do município. São poucos os fragmentos da área que são próximos entre si e possibilitam o trânsito da biota.

Dessa forma, é conveniente que todas as UCs propostas possuam corredores ecológicos, especialmente as de Proteção Integral, a fim de minimizar os efeitos deletérios da fragmentação. As áreas Palm2 e Tamanduá, além da própria APP do rio Pardo, podem promover a conectividade com outras áreas próximas, inclusive fragmentos prioritários para preservação e conservação, como as áreas A17, A19, A20, A21 e A23. Caso a vegetação nas áreas Palm2 e Tamanduá fosse restaurada, estas áreas poderiam atuar estabelecendo corredores ecológicos a nível local.

Além das UCs, os outros ETEPs também contribuem para uma maior heterogeneidade da paisagem, podendo facilitar o fluxo gênico. Exemplos são as APP de pequenos córregos e os maciços de vegetação na forma de RL, parque urbano ou ZPM. Assim, áreas como a A25 e pequenos fragmentos incluídos nos limites das áreas A13, A24 e A16 têm potencial para atuar como stepping stones.

Todavia, a gestão desses espaços precisa considerar que os corredores ecológicos implantados necessitam ser monitorados e avaliados, estimando sua real eficácia e 
eficiência, pois não é consenso na comunidade científica que os benefícios gerados por este instrumento se sobrepõem aos inconvenientes em potencial (Gustafsson \& Hansson, 1997).

Em se tratando de um conjunto de áreas protegidas, a instituição de um "mosaico" de fato, instrumento de gestão previsto pela Lei do SNUC, parece aplicável ao cenário determinado neste trabalho. Porém, apesar dos benefícios advindos do reconhecimento do mosaico, como uma gestão integrada e participativa, há as dificuldades enfrentadas.

Dentre os problemas enfrentados pelos atuais "mosaicos" reconhecidos pelo Ministério do Meio Ambiente, podem ser citadas as dificuldades de relação entre os diversos atores existentes e atuantes no mosaico. As dificuldades de relacionamento, problemas no processo de decisão, gestão centralizada, fragilidades do conselho, dificuldades de adaptação à gestão compartilhada e integração de diferentes agendas constituem desafios à gestão integrada e participativa do mosaico. A sobrecarga de ações e poucos recursos financeiros também são problemas atrelados à constituição do mosaico. Na prática, verifica-se uma grande distância entre o reconhecimento formal dos mosaicos e sua operacionalização no campo, pois há pouco envolvimento institucional, dificultando a integração efetiva das áreas que o compõe (Pinheiro, 2010). Portanto, o estabelecimento de um mosaico composto pelas UCs e outros ETEPs determinados neste trabalho demanda recursos técnicos e humanos para a sua efetiva implantação.

A seguir, cada uma das modalidades de UC determinadas foi caracterizada, a fim de se levantar aspectos mais importantes de cada modalidade. Os pontos levantados dizem respeito a problemas de criação, implementação e gestão, além da eficácia em cumprir os objetivos do SNUC e da categoria. Também foi discutido o papel social e ambiental dos outros tipos de ETEPs determinados.

\section{a. Estação Ecológica (EE)}

A EE é uma categoria restritiva de UC, onde a biodiversidade está condicionada a um maior grau de proteção, visto sua prioridade em preservar a natureza e desenvolver pesquisas científicas (Brasil, 2000). Porém, a efetividade destas áreas é dependente de uma infinidade de fatores relacionados à gestão e ao controle das ameaças e pressões sofridas (IBAMA/WWF-Brasil, 2007).

No caso do município de Ribeirão Preto, há uma experiência malsucedida com esta categoria de UC. AEE de Ribeirão Preto, mais conhecida como Mata de Santa Teresa, abriga um fragmento de 154,16 hectares, o mais rico em espécies do município. Entretanto, apesar de estar enquadrada em uma categoria tão restritiva como a EE, a Unidade permaneceu mais de 25 anos sem plano de manejo, exposta a todas as pressões de um município em crescimento. Diversas atividades conflitantes são desenvolvidas no interior da Mata, como o depósito de lixo e a visitação desordenada. Além disso, sua atual zona de amortecimento é muito pressionada pela expansão imobiliária local (Plano de Manejo EERP, 2010). Dessa forma, os objetivos desta área não são alcançados, havendo uma grande discrepância entre a realidade e o previsto pela legislação.

Portanto, a criação de EE ou categoria semelhante nas áreas A21, A23 e Tamanduá deve ser extremamente criteriosa e objetiva. A elaboração e a instituição do plano de manejo, do zoneamento e da zona de amortecimento destas áreas devem ser prioridade, a fim de evitar que estes últimos remanescentes importantes tenham o mesmo destino da EERP.

\section{b. Parque Natural Municipal (PARNA)}

O objetivo do PARNAé a preservação da natureza, realização de pesquisas científicas e desenvolvimento de atividades de recreação, educação ambiental e ecoturismo (Brasil, 2000). Dessa forma, apesar de ser UC de Proteção Integral, esta categoria permite a interação da população residente de diversas formas.

Quando próximos da expansão urbana dos municípios, os PARNA podem ser uma opção de lazer, principalmente em cidades com déficit de áreas de lazer e áreas verdes, como é o caso de Ribeirão Preto. Apesar da problemática relacionada às pressões que a urbanização exerce sobre as UCs, as mesmas devem ser integradas ao ambiente urbano quando este estiver presente em seu entorno (Mazzei et al., 2007).

As áreas A18 e A19, propostas como Parque Natural Municipal, englobam dois fragmentos importantes para preservação no contexto municipal, por se tratarem dos últimos fragmentos de cerrado em melhor estado 
de conservação e também pelo fato de abrigarem alta proporção de espécies raras deste bioma. Devido à sua grande importância para preservação, é necessário que essas áreas recebam proteção máxima na forma de UC, porém, sua relativa proximidade com centros urbanos elimina sua categorização em EE ou Reserva Biológica, onde há muitas restrições ao uso. O PARNA pode ser uma solução, pois permitiria a visitação do público, mas também teria objetivos de preservar os ecossistemas. Todos os objetivos do PARNA citados são adequados e desejáveis no contexto das áreas A18 e A19. Em relação à pesquisa científica, esta também é desejável, em razão de estas áreas incluírem os últimos remanescentes de cerrado de importância local e também devido à notável ausência de estudos de fauna e flora em Ribeirão Preto, mesmo havendo universidades que desenvolvem pesquisas nesta área do conhecimento.

A maior vantagem dos PARNA próximos ou inseridos em zona urbana é a possibilidade de acolher a população local que busca alternativas de lazer, juntamente com a promoção da conservação da natureza. Assim, é dada uma função social a essas áreas que muitas vezes são cercadas e abandonadas, o que acaba despertando na população um sentimento de rejeição em relação à "mata". Cabe ressaltar que é indispensável que haja um comprometimento com o zoneamento da Unidade, a fim de que as atividades de visitação não prejudiquem a preservação dos ecossistemas (Mazzei et al., 2007).

Dessa forma, os PARNA podem constituir espaço para educação ambiental e lazer da população do entorno, em áreas em expansão urbana, como é o caso das áreas A18 e A19. Porém, é uma categoria de Proteção Integral, onde um dos objetivos é a preservação da natureza. Assim, o regramento e o zoneamento da área são prioridades quando da criação destas UCs, visando compatibilizar a visitação com a preservação da natureza.

\section{c. Área de Relevante Interesse Ecológico (ARIE)}

AARIE é uma UC de Uso Sustentável, cujo objetivo é conservar os ecossistemas naturais de importância regional ou local, regulando o uso dessas áreas (Brasil, 2000). Porém, a legislação federal dispôs pouco sobre quais atividades são permitidas ou proibidas em uma ARIE e quais objetivos não são adequados. Dessa forma, todos os objetivos dispostos pelo SNUC são potencialmente aplicáveis a essa categoria.

Portanto, a ARIE pode abrigar atividades diversas, desde que previstas e normatizadas em seu plano de manejo. Assim, há potencial em atingir diferentes objetivos do SNUC. No caso da área de estudo, onde três ARIEs foram propostas, cada Unidade determinada pode ter um objetivo diferente, de acordo com suas características. Por exemplo, a área A17 tem potencial para desenvolver a educação ambiental e o contato com o público, dada sua proximidade a bairros residenciais, enquanto que a área Palm2 tem potencial para promover a conectividade entre os outros espaços do mosaico.

\section{d. Área de Proteção Ambiental (APA)}

A APA é uma área com certo grau de ocupação humana, onde há atributos bióticos, abióticos, estéticos ou culturais importantes para a qualidade de vida das populações. O objetivo desta categoria é proteger a biodiversidade, disciplinar o processo de ocupação e assegurar o uso sustentável dos recursos naturais da área (Brasil, 2000).

Segundo Pádua (2001), a APA é uma categoria indicada para promover o ordenamento territorial, onde terras públicas e privadas estão sob normas e restrições de acordo com o zoneamento, o qual visa normatizar ou restringir: 1) as atividades potencialmente poluidoras capazes de afetar mananciais de água, como indústrias; 2) a realização de obras que causem alterações nas condições ecológicas locais, notadamente obras de terraplanagem e abertura de canais; 3) o exercício de atividades que causem erosão e assoreamento dos rios; 4) o exercício de atividades que possam promover a extinção de espécies raras da biota regional.

A autora também menciona que esta categoria tem potencial para constituir corredores ecológicos e pode atuar como ZA de outra UC. Entretanto, a APA não é a melhor categoria quando o objetivo maior é proteger a biodiversidade, sendo que outras categorias mais restritivas proporcionam melhores condições para atingir este objetivo. Por fim, comenta que as APAs são largamente implantadas no Brasil devido aos seus atrativos, como a possibilidade de atingir amplos objetivos, ordenar o território e proteger a biodiversidade, sem que haja processo de desapropriação. Por conseguinte, muitas APAs são 
criadas sem critérios claros, dando a falsa impressão de que muitos hectares são protegidos, contudo, a realidade no campo após a criação permanece a mesma. A gestão destas áreas também é dificultosa, devido à diversidade de atores sociais envolvidos.

A instituição de uma APA na área de estudo é altamente recomendada, visto que há necessidade de compatibilizar o desenvolvimento urbano e rural desta zona do município de Ribeirão Preto com a conservação das características naturais relevantes locais. Entretanto, todo o processo pré-criação deve ser cuidadoso e criterioso, a fim de propor limites adequados. Assim, há necessidade de estudos adicionais que possam delimitar a abrangência desta APA, podendo integrar as áreas previamente enquadradas no presente trabalho.

\section{e. Zona de Proteção Máxima (ZPM) e parque urbano}

Dentre os outros ETEPs determinados, além de UCs, muitos deles se encontram inseridos na zona de expansão urbana, inclusive alguns totalmente encravados em área urbanizada. No município de Ribeirão Preto há 17 parques urbanos, dos quais sete estão implantados, ou seja, estão abertos ao público e contam com toda a infraestrutura de visitação (Guzzo et al., 2006). Nenhum destes parques implantados se localiza na ZUE, apenas um está em fase de implantação e outro não recebeu qualquer tratamento, o que mostra a carência de espaços deste tipo na região.

Os serviços ecossistêmicos de regulação do ciclo hidrológico são de grande importância no contexto do município, visto o histórico de enchentes e a presença da zona de recarga do SAG situada na ZL da cidade. Assim, as ZPMs e os parques urbanos públicos, que são parte do ecossistema urbano, podem executar esses serviços ambientais benéficos.

A ZPM é um espaço protegido específico do município de Ribeirão Preto. Trata-se uma determinada porção do território municipal, de domínio público ou privado, instituída com a finalidade de obter melhores resultados na drenagem superficial. É um espaço protegido adequado aos casos onde os corpos d'água apresentam características que sugerem uma maior frequência de inundações nas áreas lindeiras. A ZPM abrange as planícies aluvionares, as APPs, remanescentes de vegetação, dentre outras áreas, ou seja, ecossistemas que naturalmente proveem serviços ambientais, notadamente relativos ao ciclo hidrológico. Nestas áreas é vedado o parcelamento do solo, o uso residencial ou qualquer outro tipo de atividade urbana (Ribeirão Preto, 2007). Já os parques urbanos, que são áreas verdes com função ecológica, estética e de lazer, também atuam incrementando a permeabilidade do solo, pois neste espaço recomenda-se pelo menos $70 \%$ de áreas vegetadas com solo permeável (Nucci, 2008; Bargos \& Matias, 2011).

Além dos benefícios ambientais, estes ecossistemas urbanos têm outras funções, notadamente social, estética, psicológica e educativa (Bargos \& Matias, 2011). Porém, devido à falta de áreas verdes públicas para o lazer e à ausência de infraestrutura de visitação nas existentes, estes espaços terminam abandonados e são utilizados para depósito irregular de resíduos sólidos, prática de crimes e consumo de drogas, o que desperta um sentimento negativo na população em relação a estas áreas. Muitas vezes, para a comunidade local, o benefício viria com a "retirada" da mata, solucionando assim muitos dos problemas associados a ela.

$\mathrm{Na}$ própria área de estudo há exemplos de áreas verdes com problemas de manutenção por parte do Poder Público Municipal, como o Parque "Cidade das Crianças", que no passado era ponto de encontro de famílias e hoje está abandonado, servindo de depósito para todo tipo de lixo e abrigo para usuários de drogas. Em outros pontos da ZUE é comum a presença de lixo e entulho na borda dos fragmentos de vegetação. Apesar dos problemas relativos a estes espaços em Ribeirão Preto, o município abriga exemplos bem-sucedidos de parques urbanos de uso público, cuja valorização e identificação pela sociedade ribeirão-pretana são altas. Um exemplo é o Parque Prefeito Luiz Roberto Jábali, mais conhecido como "Parque Curupira". Localizado em uma área que antigamente abrigava uma pedreira desativada, onde havia proliferação de vetores, fogo e crimes de diversas naturezas, hoje o parque constitui um dos pontos mais valorizados e visitados do município. Nota-se, portanto, a transformação de uma área obsoleta e indesejada em espaço de grande uso público e valorização do capital (Gomes, 2011). 
O exemplo do Parque Curupira pode ser aplicado quando do planejamento de outras áreas de lazer no município, principalmente nas áreas propostas neste trabalho para integrar parque urbano de uso público. A área $\mathrm{A} 16 \mathrm{~b}$ possui características semelhantes às do Parque Curupira: abriga uma pedreira desativada, espaços livres e fragmento remanescente de mata decídua.

\section{Conclusão}

As áreas prioritárias sugeridas pelo cenário obtido por Bircol (2012), o qual constava de 30 diferentes áreas contínuas que abrigavam fragmentos de vegetação, APPs, áreas de cultura agrícola, dentre outros tipos de uso do solo, puderam ser qualificadas e categorizadas em modalidades de ETEPs. Algumas áreas possuem alto potencial para preservação da biota e dos recursos naturais, podendo ser enquadradas em áreas protegidas mais restritivas, como Unidades de Conservação, enquanto que outras áreas têm potencial para o uso público da população do entorno. Dessa forma, a implantação de espaços protegidos na ZUE na forma de mosaico proposto por este trabalho pode permitir o alcance de diversos objetivos na área de estudo, por meio da proteção destas

\section{Referências}

Bargos, D. C.; Matias, L. F. Áreas verdes urbanas: um estudo de revisão e proposta conceitual. Revista da Sociedade Brasileira de Arborização Urbana, 6(3), 172-188, 2011. Disponível em: <http://www.revsbau.esalq.usp.br/artigos_cientificos/ artigo169-publicacao.pdf $>$.

Bergkamp, G.; Cross, K. Groundwater and Ecosystem Services: Towards Their Sustainable Use. In: Proceedings of International Symposium on Groundwater Sustainability (ISGWAS). Alicante, jan. 2006.

Bircol, G. A. C. Determinação de áreas especiais de preservação em uma zona de recarga do Sistema Aquifero Guarani, no município de Ribeirão Preto (SP). Ribeirão Preto, Monografia (Bacharelado em Biologia) - FFCLRP-USP, 2012.

Bonton, A.; Rouleau, A.; Bouchard, C.; Rodriguez, M. J. Assessment of groundwater quality and its variations in áreas prioritárias e consequente manutenção dos serviços ecossistêmicos prestados.

Em relação à população da ZUE, esta seria beneficiada pelas funções ambiental, social, estética, psicológica e educativa relativas aos ecossistemas urbanos. Sobre a conservação do $\mathrm{SAG}$, a recuperação da vegetação nos ETEPs propostos poderia promover a regulação do ciclo hidrológico executada pelos ecossistemas. Já em áreas prioritárias maiores localizadas sobre o afloramento, com uma diversidade de usos do solo, o estabelecimento de diretrizes específicas em relação às atividades humanas poderia evitar que o cultivo da cana-de-açúcar provoque a contaminação da água subterrânea. Neste último caso, a APA é o ETEP adequado para realizar o ordenamento territorial.

O presente trabalho gerou um mosaico de ETEPs, estabelecendo diretrizes e prioridades a serem tomadas quando da criação destes espaços. Dessa forma, a instituição de um mosaico de espaços protegidos pode conferir proteção especial a áreas ambientalmente frágeis ou ameaçadas, como é o caso da ZUE do município de Ribeirão Preto. Apesar de aplicada a uma região específica, a metodologia aqui apresentada também pode ser empregada em qualquer outra região, cabendo apenas ajustes relacionados à realidade local.

the capture zone of a pumping well in an agricultural area. Agricultural Water Management, 97(6), 824-834, 2010. DOI: 10.1016/j.agwat.2010.01.009.

Brasil. Lei $n^{\circ}$ 9.985, de 18 de julho de 2000. Regulamenta o art. $225, \S 1^{\circ}$, incisos I, II, III e VII da Constituição Federal, institui o Sistema Nacional de Unidades de Conservação da Natureza e dá outras providências. Brasília: DOU de 19/07/2000.

Coletti, R. N. A participação da sociedade civil em instrumentos da política ambiental brasileira. Desenvolvimento e Meio Ambiente, 25, 39-51, 2012. Disponível em: <http://ojs.c3sl.ufpr. br/ojs/index.php/made/article/view/25544/18572>.

Gomes, M. A. F.; Filizola, H. F.; Spadotto, C. A. Classificação das áreas de recarga do Sistema Aquífero Guarani no Brasil em domínios pedomorfo agroclimáticos - Subsídio aos estudos de avaliação de risco de contaminação das águas subterrâneas. 
Revista do Departamento de Geografia, 18, 67-74, 2006. Disponível em: <http://www.geografia.fflch.usp.br/publicacoes/ RDG/RDG_18/RDG18_067_074.pdf $>$.

Gomes, M. A. S. Parque Prefeito Luiz Roberto Jábali e o processo de produção do espaço urbano em Ribeirão Preto-SP, Brasil. Revista Geográfica de América Central, 2(47E), 1-18, 2011. Disponível em: <http://www.revistas.una.ac.cr/index. php/geografica/article/view/2204>.

Google Earth. Disponível em: <www.google.com/earth/index. html $>$.

Goulart, M. P.; Campos, H. C. N. S.; Nepomuceno, O. Tutela jurídica do Aquífero Guarani em Ribeirão Preto (Estado de São Paulo, Brasil). Boletín Geológico y Minero, 123(3), 389399, 2012. Disponível em: <http://www.igme.es/internet/ Boletin/2012/123_3/18_ARTICULO\%2014.pdf>.

GT-ZUE (Grupo de Trabalho da Zona de Uso Especial). Relatório técnico do Grupo de Trabalho - Diretrizes Ambientais e Urbanísticas para a ZUE. Ribeirão Preto, 2010.

Gustafsson, L.; Hansson, L. Corridors as a conservation tool. Ecological Bulletins, 46, 182-190, 1997.

Guzzo, P.; Carneiro, R. M. A.; Júnior, H. O. Cadastro municipal de espaços livres urbanos de Ribeirão Preto (SP): acesso público, índices e base para novos instrumentos e mecanismos de gestão. Revista da Sociedade Brasileira de Arborização Urbana, 1(1), 19-30, 2006. Disponível em: <http://www.revsbau. esalq.usp.br/artigos_cientificos/artigo03.pdf $>$.

IBAMA/WWF-Brasil. Efetividade de gestão das Unidades de Conservação federais do Brasil. 2007. Disponível em: $<$ www.mma.gov.br/estruturas/pda/_arquivos/prj_mc_061_ pub_liv_002_uc.pdf $>$. Acesso em: out. 2012.

IBGE - Instituto Brasileiro de Geografia e Estatística. Mapas. Disponível em: <mapas.ibge.gov.br/>. Acesso em: dez. 2013.

Kotchetkoff-Henriques, O. Caracterização da vegetação natural em Ribeirão Preto, SP: bases para a conservação. Ribeirão Preto, Tese (Doutorado em Ciências) - FFCLRP-USP, 2003.

Leite, J. R. M.; Ávila, C.; Fontana, L. Estação ecológica e reserva biológica: Direito Ambiental posto ou aplicado? In: Benjamin, A. H. (Coord.). Direito ambiental das áreas protegidas: o regime jurídico das unidades de conservação. Rio de Janeiro: Forense Universitária, 2001.

Mazzei, K.; Colesanti, M. T. M.; Santos, D. G. Áreas verdes urbanas: espaços livres para o lazer. Sociedade \& Natureza, 19(1), 33-43, 2007. Disponível em: <http://www.seer.ufu.br/ index.php/sociedadenatureza/article/view/9350/5730>.
Nucci, J. C. Qualidade ambiental e adensamento urbano: um estudo de ecologia e planejamento da paisagem aplicado ao distrito de Santa Cecília (MSP). 2. ed. Curitiba: O Autor, 2008.

OEA - Organização dos Estados Americanos. Síntese hidrológica do Aquifero Guarani. 2009. 105 p. (Série Manuais e Documentos Técnicos do Projeto de Proteção Ambiental e Desenvolvimento Sustentável do Sistema Aquífero Guarani).

Pádua, M. T. J. Área de proteção ambiental. In: Benjamin, A. H. (Coord.). Direito ambiental das áreas protegidas: o regime jurídico das unidades de conservação. Rio de Janeiro: Forense Universitária, 2001.

Peccatiello, A. F. O. Políticas públicas ambientais no Brasil: da administração dos recursos naturais (1930) à criação do Sistema Nacional de Unidades de Conservação (2000). Desenvolvimento e Meio Ambiente, 24, 71-82, 2011. Disponível em: $<$ http://ojs.c3sl.ufpr.br/ojs2/index.php/made/article/ view/21542/17081>.

Pereira, P. F.; Scardua, F. P. Espaços territoriais especialmente protegidos: conceito e implicações jurídicas. Ambiente \& Sociedade, 11(1), 81-97, 2008. DOI: 10.1590/S1414-753X2008000100007.

Pinheiro, M. R. (Org.). Recomendações para reconhecimento e implementação de mosaicos de áreas protegidas. 2010. Disponível em: $<$ www.conservation.org.br/publicacoes/files/recomendacoes_mosaicos_completo.pdf $>$. Acesso em: out. 2012.

Pizella, D. G.; Souza, M. P. Análise dos aspectos institucionais da regulação de OGMs no Brasil: boas práticas de governança ambiental? Desenvolvimento e Meio Ambiente, 25, 27-37, 2012. Disponível em: <http://ojs.c3sl.ufpr.br/ojs2/index.php/ made/article/view/25495>.

Plano de Manejo EERP. Plano de Manejo da Estação Ecológica de Ribeirão Preto: volume principal e anexos. 2010. Disponível em: <fflorestal.sp.gov.br/files/2012/01/EERP-Vol-principal. pdf $>$. Acesso em: out. 2012.

Primack, R. B.; Rodrigues, E. Biologia da conservação. Gráfica e Editora Vida, 2002.

Ranieri, V. E. L. Reservas Legais: critérios para localização e aspectos de gestão. São Carlos, Tese (Doutorado em Ciências da Engenharia Ambiental) - EESC-USP, 2004.

Rebouças, A. C.; Amore, L. O Sistema Aquífero Guarani SAG. Águas Subterrâneas, 16(1), 135-143, 2002. Disponível em: <http://aguassubterraneas.abas.org/asubterraneas/article/ view/1306/1084>.

Ribeirão Preto. Lei complementar $n^{\circ} 2157$, de 31 de janeiro de 2007. Dispõe sobre o parcelamento, uso e ocupação do 
solo no município de Ribeirão Preto. Disponível em: <www. ribeiraopreto.sp.gov.br/principaln.php?pagina=/leis/pesquisa/ ver.php?id=21377>. Acesso em: dez. 2013.

Ribeiro, M. F.; Freitas, M. A. V.; Costa, V. C. O desafio da gestão ambiental de zonas de amortecimento de unidades de conservação. In: Anais do Seminário Latino-Americano de Geografia Física. Coimbra, 6 de maio de 2010.

Saes, B. M.; Miyamoto, B. C. B. Limites físicos do crescimento econômico e progresso tecnológico: o debate The Limits to Growth versus Sussex. Desenvolvimento e Meio Ambiente, 26, 51-68, 2012. Disponível em: <http://ojs.c3sl.ufpr.br/ojs2/ index.php/made/article/view/26808/19671>.

São Paulo (Estado). Secretaria do Meio Ambiente. Instituto Florestal. Inventário florestal da vegetação natural do Estado de São Paulo. Mapa florestal dos municípios do Estado de São Paulo: Ribeirão Preto. 2009. Disponível em: <www. iflorestal.sp.gov.br/sifesp/estadosaopaulo/ribeiraopreto. pdf?opcoes $=$ estadosaopaulo/ribeiraopreto.pdf $>$. Acesso em: jun. 2013.
Sekercioglu, C. H. Ecosystem functions and services. In: Sodhi, N. S.; Ehrlich, P. R. (Ed.). Conservation biology for all. Oxford: Oxford University Press, 2010. 358 p.

Shafer, C. L. Terrestrial nature reserve design at the urban/ rural interface. 1997. In: Marzluff; J. M.; Shulenberger, E.; Endlicher, W.; Alberti, M.; Bradley, G.; Ryan, C.; Simon, U.; Zumbrunnen, C. Urban ecology: an international perspective on the interaction between humans and nature. New York: Springer, 2008.

Villar, P. C.; Ribeiro, W. C. Sociedade e gestão do risco: o Aquífero Guarani em Ribeirão Preto-SP, Brasil. Revista de Geografia Norte Grande, 43, 51-64, 2009. DOI: 10.4067/ S0718-34022009000200003.

Zhang, H.; Hiscock, K. M. Modelling the effect of forest cover in mitigating nitrate contamination of groundwater: A case study of the Sherwood Sandstone aquifer in the East Midlands, UK. Journal of Hydrology, 399(3-4), 212-225, 2011. DOI: 10.1016/j.jhydrol.2010.12.042. 